\title{
TEMPERATURAS DE SUPERFÍCIE DOS OCEANOS PACÍFICO E ATLÂNTICO: INFLUÊNCIAS NAS ANOMALIAS DE CHUVA NA MICRORREGIÃO DE VITÓRIA DE SANTO ANTÃO, PERNAMBUCO
}

\author{
RIBEIRO, Eberson Pessoa - ebersonpessoa@recife.ifpe.edu.br \\ Instituto Federal de Pernambuco / IFPE
}

MACIEL, Amanda S. Quirino De Alcântara - amandadealcantaramaciel@gmail.com Instituto Federal de Pernambuco / IFPE

MOREIRA, Elvis Berg Mariz - elvis.moreira@ufob.edu.br

Universidade Federal do Oeste da Bahia / UFOB

PACHECO, Admilson da Penha - pacheco3p@gmail.com

Universidade Federal de Pernambuco / UFPE

Submetido em: $22 / 07 / 2020$

Aceito para publicação em: 31/05/2021

Publicado em: 08/06/2021

DOI: http://dx.doi.org/10.5380/abclima.v28i0.75389

\begin{abstract}
RESUMO: O estudo do comportamento da pluviosidade é fundamental, pois possibilita detectar e comparar tendências e/ou alterações climáticas em variadas escalas. 0 presente trabalho teve como objetivo analisar a correlação das Anomalias de Temperatura da Superfície do Mar (ATSM) nos oceanos Pacífico e Atlântico e as Anomalias de Chuvas (IAC) na microrregião de Vitória de Santo Antão-PE. Para tal, foram utilizados os valores médios mensais da precipitação da série histórica de 1960 a 2015 de 5 estações. Assim, analisou-se a variabilidade da precipitação por meio do IAC, como também se examinou os padrões de teleconexões das ATSMs dos oceanos, além do Índice PA e suas influências na variabilidade pluviométrica. Os resultados alcançados constataram que a microrregião estudada possui uma diminuição da precipitação, apresentando irregularidades interanuais e sazonais. Foi possível observar uma relação expressiva entre as ATSMs e do índice PA com o IAC, além de diferentes graus de influência das regiões do NINO sobre as chuvas ou secas na área. O GRADT apresentou expressivo aumento na TSM no NATL e de maneira mais modesta no SATL. Verificou-se também relação inversa do GRADT com o IAC, pois quando o GRADT se apresenta positivo ocorre IAC negativo e vice-versa.
\end{abstract}

PALAVRAS-CHAVE: ATSM; IAC; Índice PA; Teleconexões; variabilidade pluviométrica

SURFACE TEMPERATURES OF THE PACIFIC AND ATLANTIC OCEANS: INFLUENCES ON RAIN ANOMALIES IN THE VICTORY MICRO-REGION OF SANTO ANTÃO, PERNAMBUCO

ABSTRACT: Studying rainfall behavior is fundamental, as it allows detecting and comparing trends and / or climatic changes at various scales. The present work aimed to analyze the correlation of Sea Surface Temperature Anomalies (ATSM) in the Pacific and Atlantic oceans and the Rain Anomalies (RAI) in the micro region of Vitória de Santo Antão, Pernambuco. For this, the monthly average rainfall values of the historical series from 1960 to 2015 of 5 weather stations were used. Thus, rainfall variability through IAC and the teleconnection patterns of ocean ATSMs were analyzed, as well as the PA Index and their influence on rainfall variability. The results showed that the microregion under study has reduced tasinfall, presenting interannual and seasonal irregularities. Significant relationship between ATSMs and the PA index and IAC was observed, in addition to different degrees of influence of NINO regions on rainfall or drought in the area. GRADT showed significant increase in TSM in NATL and more modestly in SATL. There was also 
an inverse relationship between GRADT and IAC, since when GRADT is positive, negative IAC occurs and vice versa.

KEYWORDS: ATSM; RAI; PA Index; Teleconnections; Rainfall variability.

TEMPERATURAS DE SUPERFICIE DE LOS OCÉANOS PACÍFICO Y ATLÁNTICO: INFLUENCIAS EN ANOMALÍAS DE LLUVIAS EN LA MICRORREGIÓN DE VITÓRIA DE SANTO ANTÃO, PERNAMBUCO

RESUMEN: El estudio del comportamiento del índice pluviométrico es fundamental, pues posibilita detectar y comparar tendencias y/o alteraciones climáticas en varias escalas. El presente trabajo tuvo como objetivo analizar la correlación de las Anomalías de la Temperatura de la Superficie del Mar (ATSM) en los océanos Pacífico y Atlántico y las Anomalías de la Lluvia (IAC) en la micro región de Vitória de Santo Antão, Pernambuco. Para eso, se usaron los valores promedios mensuales de la precipitación de laserie histórica de 1960 a 2015 de 5 estaciones. De ese modo, se analizóla variación de la precipitación por medio del IAC, como también se examinaron losestándares de teleconexiones de las ATSMs de los océanos, además del Índice PA y su influenciaen la variación pluviométrica. Los resultados alcanzados mostraron que la microrregión estudiada posee una disminución de laprecipitación, presentando irregularidades interanuales yestacionales. Fue posible observar una relación destacada entre las ATSMs y el índice PA con el IAC, además de diferentes grados de influencia de las regiones del NIÑO sobre las lluvias o secas enel área. El GRADT presentó unimportante aumento en la TSM en el NATL y de manera más modesta en el SATL. Se verifico también relación contraria del GRADT conel IAC, pues cuando el GRADT se presenta positivo ocurre IAC negativo y viceversa.

PALABRAS CLAVE: ATSM; IAC; Índice PA; Teleconexiones; Variación pluviométrica

\section{INTRODUÇÃO}

Os múltiplos sistemas atmosféricos atuantes no Nordeste do Brasil (NEB) provocam grande diversidade climática nessa região, sendo responsáveis pela intensidade das chuvas, bem como pela variabilidade sazonal e interanual. 0 monitoramento de períodos chuvosos e secos e da variabilidade espaço-temporal da precipitação são essenciais para a gestão de recursos hídricos. Segundo Sant'Anna Neto (1998), a variabilidade e a irregularidade das precipitações, bem como as excepcionalidades dos eventos climáticos interferem intensamente nas atividades econômicas, além de exercer forte influência na transformação da paisagem, sendo de "capital importância dispor-se de instrumental prático de auxílio à tomada de decisões" (FREITAS, 2005, p. 84).

A compreensão do comportamento da precipitação pluviométrica é fundamental, uma vez que possibilita detectar tendências ou alterações climáticas em variadas escalas, além de compará-las (MARCUZZO; GOULARTE, 2012). O Índice de Anomalia de Chuva (IAC) foi desenvolvido por Rooy (1965) com a finalidade de caracterizar e monitorar a variabilidade espaço-temporal da precipitação de uma região, como também classificar as magnitudes de anomalias de precipitações positivas e negativas, permitindo a comparação entre as condições atuais e as séries históricas em consonância à intensidade dos eventos.

Dentro desse contexto a análise das variações de Temperatura da Superfície do Mar (TSM) nos oceanos Atlântico e Pacífico, bem como sua influência sob as anomalias de chuva são de grande importância para estudos de comportamento pluviométrico (OLIVEIRA; MARCUZZO; BARROS, 2015). Barreiro; Chang; Saravanan (2002) afirmam que a TSM tem papel significativo na 
variabilidade da precipitação, demonstrando, em muitos casos, mais influência que as condições da atmosfera, pois estão diretamente ligadas ao acúmulo de energia e fonte de umidade para retroalimentação de sistemas convectivos. Assim, verifica-se que as mudanças climáticas podem ocorrer impulsionadas pelas circunstâncias da TSM do Pacífico e Atlântico (SILVA et al., 2017).

Uvo et al. (1994) obtiveram evidências de que em anos extremamente secos ou extremamente chuvosos no NEB ocorreram em associação com valores de anomalias altas e baixa da TSM no Pacífico Equatorial e no Atlântico Sul. Vários estudos como os de Hastenrath; Heller (1977), Nóbrega; Santiago (2014), Oliveira; Marcuzzo; Barros (2015) e Silva et al. (2017) vêm correlacionando a dependência de precipitação do NEB a eventos ocasionados pela TSM dos oceanos Atlântico e/ou Pacífico. Ribeiro; Lunardi (1997) destacam a importância de caracterizar a precipitação pluviométrica de um local para o planejamento de diversas atividades essenciais a sociedade. Contudo, a previsão de períodos chuvosos e secos fica comprometida devido à anormalidade de eventos atmosféricos ocasionados pela mudança da temperatura da superfície do mar. Portanto, o presente estudo busca evidenciar as anomalias da TSM sobre os oceanos Atlântico e Pacífico com as mudanças nos valores extremos de precipitação na microrregião de Vitória de Santo Antão.

O NEB tem uma alta variabilidade do regime pluviométrico. Nos últimos anos várias pesquisas (RIBEIRO, 2016; SANTOS et al., 2016; ALVES et al., 2017) vêm apontando uma correlação das anomalias de temperatura na superfície do mar (ATSMs) nos oceanos Atlântico e Pacífico sobre os eventos extremos de precipitação e secas severas, tais fenômenos exigem monitoramento desses ciclos de anos rigorosamente úmidos e anos severamente áridos na região. Essas teleconecções das ATSMs com a distribuição pluviométrica no NEB ocorrem devido à relação das precipitações com a circulação atmosférica de grande escala (oceano/atmosfera) dos oceanos Pacífico e Atlântico.

Alguns eventos atmosféricos sofrem influência direta das TSM dos oceanos Pacífico e/ou Atlântico e são responsáveis pela escassez ou abundância de chuvas no Nordeste Brasileiro, como o El Niño (ENOS positivo), a La Niña (ENOS negativo), o Dipolo do Atlântico (positivo e negativo) e a Zona de Convergência Intertropical (ZCIT). No NEB a precipitação e o conhecimento de sua variabilidade são de extrema importância, pois exercem forte influência nos setores sociais e econômicos, principalmente nas atividades agrícolas (ALVES et al., 2017SILVA et al. 2017).

Assim, buscou-se investigar a correlação das Anomalias de Temperatura da Superfície do Mar (ATSM) nos oceanos Pacífico e Atlântico e as anomalias de chuvas (IAC) na microrregião de Vitória de Santo Antão-PE. Para atingir tal objetivo foi realizada a análise da variabilidade sazonal da precipitação por meio do IAC; examinaram-se os padrões de teleconexões das ATSM dos oceanos Pacífico e Atlântico e a variabilidade precipitação; e verificou-se a influência do Índice PA (Pacífico-Atlântico) na variabilidade pluviométrica da microrregião. 


\section{MATERIAIS E MÉTODOS}

A área a ser pesquisada é a microrregião de Vitória de Santo Antão que está localizada no centro da Mesorregião da Mata de Pernambuco, na qual compõe os municípios de Chã de Alegria, Glória do Goitá, Vitória de Santo Antão, Pombos e Chã Grande (Figura 1). Os elementos de precipitação pluviométrica e temperatura do ar foram a base climatológica para a elaboração dos parâmetros a serem pesquisados. Dessa forma foram utilizados neste estudo os valores médios mensais da precipitação da série histórica de 1960 a 2015, medidos de 5 estações distribuídas na microrregião a ser examinada (Figura 1). Os dados foram obtidos por meio da Agência Pernambucana de Águas e Clima (Apac).

Para o preenchimento de dados em falta nas séries empregou-se o Método da Ponderação Regional de Bertoni e Tucci (2001), expressa na Equação 1:

$Y=1 / 3 \cdot(x 1 / x m 1+x 2 / x m 2+x 3 / x m 3) \cdot y m$

em que: $Y$ é a precipitação do posto a ser estimado; $x 1, x 2$ e x3 são as precipitações correspondentes ao mês ou ano que se deseja preencher, observadas em três estações vizinhas; xm1, xm2 e xm3 são precipitações médias nas três estações vizinhas; e ym é a precipitação média do ponto a ser estimado.

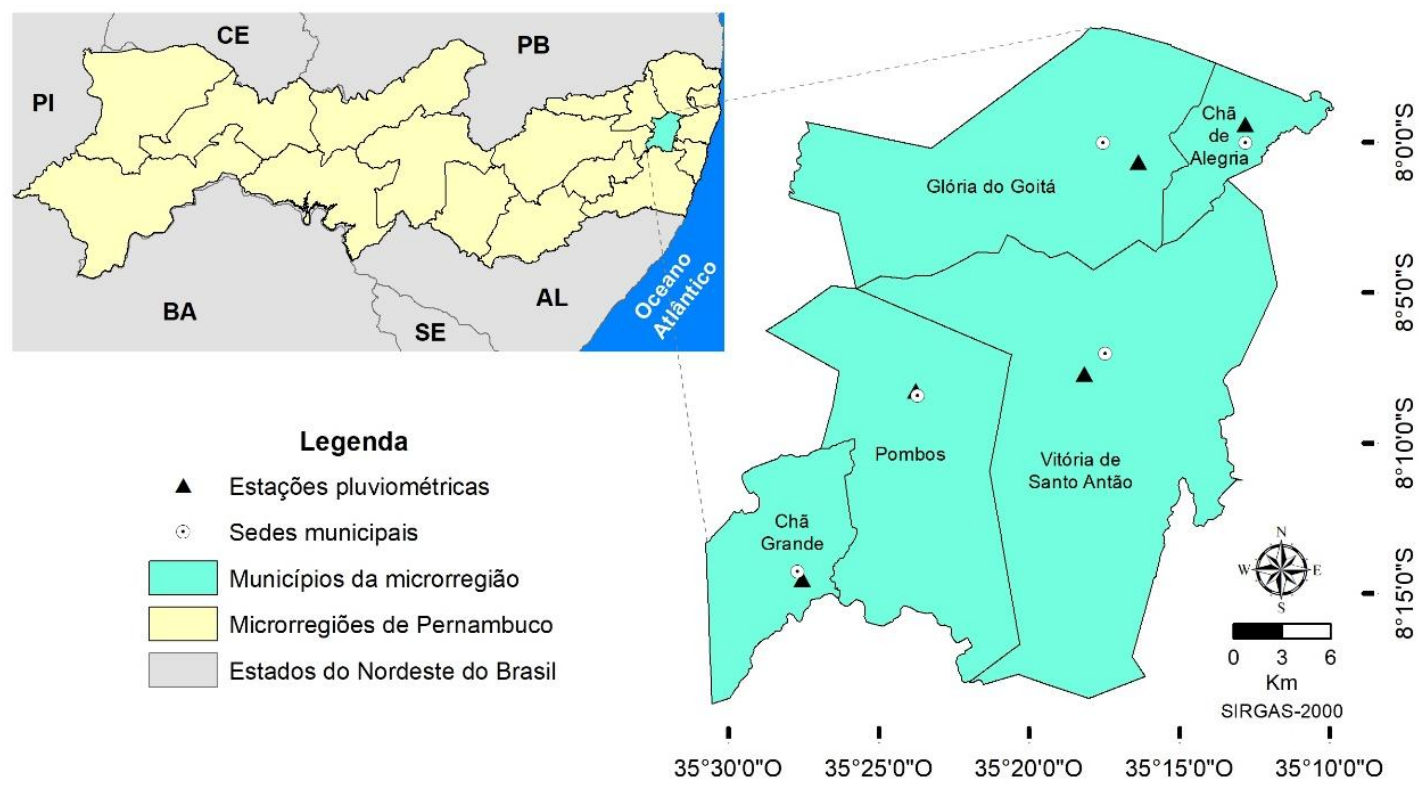

Figura 1 - Localização da microrregião de Vitória de Santo Antão.

A base de cálculo do Índice de Anomalia de Chuva (IAC) é técnica eficaz na avaliação variabilidade sazonal e interanuais da precipitação pluviométrica, sendo possível comparar desvios em relação à condição normal por meio das Equações 2 e 3 (ROOY, 1965):

IAC $=3\left[\frac{N-\bar{N}}{\bar{M}-\bar{N}}\right]$, para anomalias positivas 
IAC $=-3\left[\frac{\mathrm{N}-\overline{\mathrm{N}}}{\overline{\mathrm{X}}-\overline{\mathrm{N}}}\right]$, para anomalias negativas

em que: $\mathrm{N}=$ precipitação anual atual $(\mathrm{mm}) ; \overline{\mathrm{N}}=$ precipitação média anual da série histórica $(\mathrm{mm}) ; \overline{\mathrm{M}}=$ média das dez maiores precipitações anuais da série histórica $(\mathrm{mm}) ;$ e $\overline{\mathrm{X}}=$ média das dez menores precipitações anuais da série histórica $(\mathrm{mm})$.

Ressalta-se que o cálculo desse índice depende da média de precipitação da área e que as anomalias positivas e negativas são valores acima ou abaixo da média da média, respectivamente. Assim, assume-se que essa distribuição obedece a uma curva normal, em sino, e que os desvios para seco ou úmido são relativos, em função do comportamento climático dos postos pluviométricos estudados, e não de fato de uma separação entre o que se considera úmido ou seco de uma forma global para o conjunto de tipos climáticos do globo. Os valores do IAC foram ordenados conforme a classificação de anos secos e úmidos proposto por Rooy (1965) com a adaptação de Freitas (2004; 2005) para o NEB (Tabela 1).

Tabela 1 - Classes de Intensidade do Índice de Anomalia de Chuva

\begin{tabular}{c|cc} 
& Faixa do IAC & Classe de Intensidade \\
\cline { 2 - 3 } Índice de Anomalia & De 4 acima & Extremamente Úmido \\
de Chuva (IAC) & 2 a 4 & Muito Úmido \\
& 0 a 2 & Úmido \\
& 0 a -2 & Seco \\
& -2 a -4 & Muito Seco \\
& De -4 abaixo & Extremamente Seco
\end{tabular}

Fonte: Araújo; Moraes Neto; Souza (2009, p.96).

Com os resultados obtidos com o IAC, eventos extremos de chuvas e secas severas, foram analisados e comparados os dados de Anomalias de Temperatura da Superfície do Mar (ATSM) dos oceanos Pacífico, das regiões $\mathrm{NINO} 1+2\left(0-10^{\circ} \mathrm{S}, 90^{\circ} \mathrm{W}-80^{\circ} \mathrm{W}\right)$, NINO3 ( $\left.5^{\circ} \mathrm{N}-5^{\circ} \mathrm{S}, 150^{\circ} \mathrm{W}-90^{\circ} \mathrm{W}\right)$, NINO4 $\left(5^{\circ} \mathrm{N}-5^{\circ} \mathrm{S}, 160^{\circ} \mathrm{E}-150^{\circ} \mathrm{W}\right)$ e NINO3.4 ( $\left.5^{\circ} \mathrm{N}-5^{\circ} \mathrm{S}, 170^{\circ} \mathrm{W}-120^{\circ} \mathrm{W}\right)$; e Atlântico Norte $\left(5^{\circ} \mathrm{N}-20^{\circ} \mathrm{N}, 30^{\circ} \mathrm{E}-60^{\circ} \mathrm{W}\right)$ e Sul $\left(0^{\circ}-20^{\circ} \mathrm{S}, 30^{\circ} \mathrm{W}-10^{\circ} \mathrm{E}\right)$, derivados do Climate Prediction Center (CPC) do National Oceanic and Atmospheric Administration (NOAA), os quais são disponibilizados nos links http://www.cpc.ncep.noaa.gov/data/indices/sstoi.indices http://www.cpc.ncep.noaa.gov/data/indices/sstoi.atl.indices, respectivamente.

Desenvolvido por Lucena (2017), o Índice PA (Pacífico-Atlântico) consiste na interação oceânica por meio dos padrões de teleconexões em escala global, uma vez que provoca variabilidade climática em diversas regiões do planeta. Para o cálculo desse índice foi empregado os dados mensais de ATSM dos oceanos Pacífico e Atlântico. O primeiro cômputo consistirá na média aritmética das ATSM das regiões do NINO. Já para a ATSM do Atlântico foi calculado o Gradiente do Atlântico (GRADT), através da equação 3: GRADT = ATN - ATS (3), sendo: ATN a Anomalia de Temperatura da Superfície do Mar do oceano Atlântico Norte $\left(5^{\circ} \mathrm{N}-20^{\circ} \mathrm{N}, 30^{\circ} \mathrm{E}-60^{\circ} \mathrm{W}\right)$; e ATS a Anomalia de Temperatura da Superfície do Mar do oceano Atlântico Sul ( $\left.0^{\circ}-20^{\circ} \mathrm{S}, 30^{\circ} \mathrm{W}-10^{\circ} \mathrm{E}\right)$.

Com a análise das ATSM dos oceanos Pacífico e Atlântico foi possível chegar ao índice PA, o qual discorre de uma relação construtiva (anomalias de TSM entre esses oceanos são favoráveis à ocorrência de chuvas acima da média) ou destrutiva (favorável à ocorrência de chuvas abaixo da média). A relação construtiva teórica 
ideal considera o seguinte: Condição 1: ATSM negativa sobre o Pacífico tropical (La Niña) e Condição 2: índice GRADT negativo, indicando ATSM superior no Atlântico tropical sul. Já a relação destrutiva teórica ideal pondera também duas categorias: Condição 1: ATSM positiva sobre o Pacífico tropical (El Niño) e Condição 2: índice GRADT positivo, indicando ATSM superior no Atlântico tropical norte. O índice PA reside na soma da média de ATSM das regiões do El Niño com o índice GRADT. Ao apreciar as relações teóricas estabelecidas, sabe-se que os resultados negativos indicam uma tendência favorável à ocorrência de chuvas acima da média a medida que resultados positivos apontam uma tendência favorável à ocorrência de chuvas abaixo da média. Portanto, foram somados os valores de ATSM (positivo ou negativo) do oceano Pacífico com o Gradiente do Atlântico (GRADT), conforme as Equações 5, 6, 7, 8 e 9 (LUCENA, 2017):

PA_Média $=$ média das ATSM do oceano Pacífico + GRADT

PA_1+2 = ATSM na região do NINO1+2 + GRADT

PA_3 = ATSM na região do NINO3 + GRADT

PA_4 = ATSM na região do NINO4 + GRADT

PA_3.4 = ATSM na região do NINO3.4 + GRADT

Os quocientes encontrados do índice PA foram correlacionados ao IAC, desconsiderados os índices de Média_ENOS entre $-0,5$ e 0,5 e os índices do GRADT entre $-0,3$ e 0,3, por serem considerados anos neutros.

\section{RESULTADOS E DISCUSSÃO}

O tratamento dos dados dos elementos de precipitação e temperatura do ar possibilitou construir o climograma da microrregião de Vitória de Santo Antão para o período de 1960 a 2015 (Figura 2). O climograma revela que os meses de menor temperatura do ar se concentram entre junho a setembro, não ultrapassaram os $23^{\circ} \mathrm{C}$. Os meses de maiores temperaturas ocorrem de dezembro a março com aproximadamente $25^{\circ} \mathrm{C}$. A temperatura média anual da área é de $24^{\circ} \mathrm{C}$. A precipitação média anual é de $1.068 \mathrm{~mm}$, em que o período chuvoso acontece entre abril e julho (quadra chuvosa), responsável por cerca de $58 \%$ do total anual com $616,5 \mathrm{~mm}$. Junho é o mês mais chuvoso com uma média de $188,8 \mathrm{~mm}$. De setembro a dezembro é período mais seco, no qual a pluviosidade total foi $145 \mathrm{~mm}$, representando apenas $13,6 \%$ do total precipitado anualmente. Outubro é caracteristicamente o mês de menor precipitação com $27,9 \mathrm{~mm}$. 


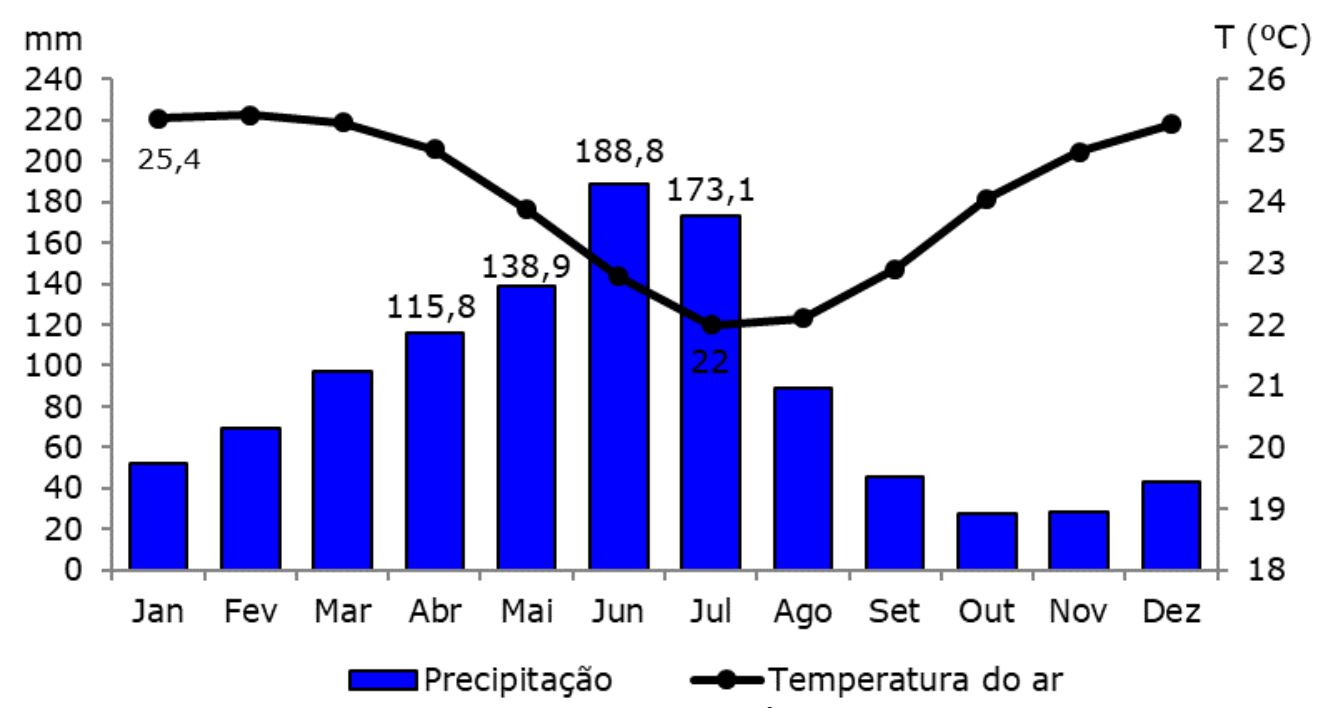

Figura 2 - Climograma da microrregião de Vitória de Santo Antão (1960-2015).

A variabilidade interanual da precipitação está representada na Figura 3. A precipitação média anual da microrregião é de $1077 \mathrm{~mm}$. Dos 56 anos investigados 25 anos foram com precipitação inferior à média e 31 anos acima. Apesar disso, observa-se uma diminuição da pluviosidade na região por meio da linha de tendência linear, bem como períodos prolongados de secas extremas (1960-1963, 1979-1983, 1990-1993, 1996-1999, 2006-2008 e 2014...). Até a década de 1970 há uma tendência de aumento das chuvas, contudo a partir de 1980 a uma inversão na tendência tornando-a negativa. Os maiores valores de precipitação observados ocorreram nos anos de 1986 (1595 mm), $2000(1457 \mathrm{~mm})$ e 1978 (1450,8mm), enquanto as menores aconteceram em 1998 (445,2 mm), 1993 (510 mm) e 1999 $(636,9 \mathrm{~mm})$. Molion e Bernardo (2000); Alencar, Barbosa e Sousa, (2007); Alves et al. (2015); Ribeiro (2016) vêm ressaltando as teleconecções entre os eventos de El Niño e La Niña com os períodos secos e chuvosos no NEB, respectivamente, bem como suas intensificas.

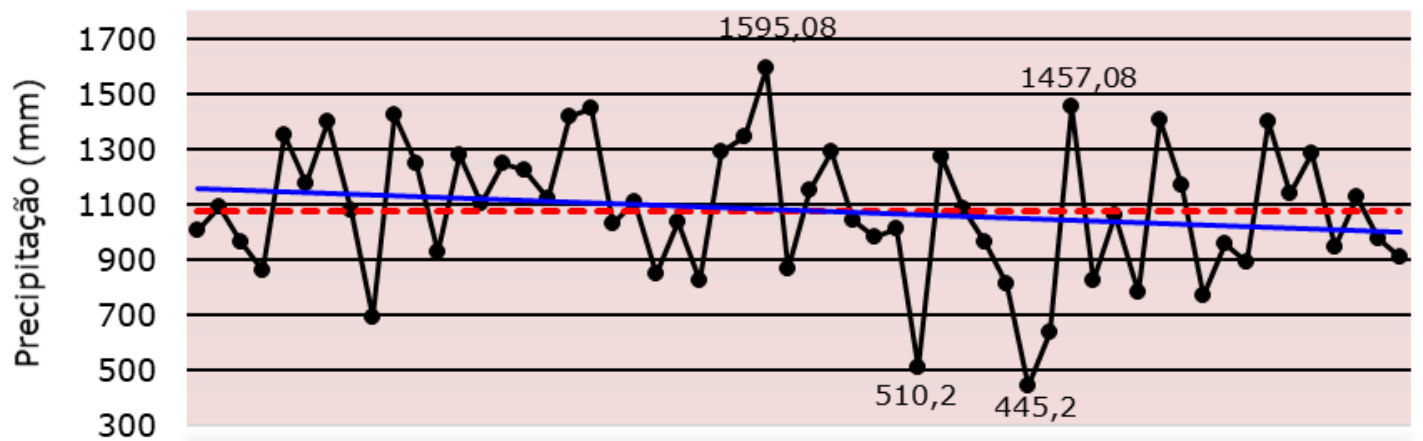

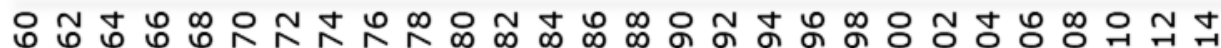

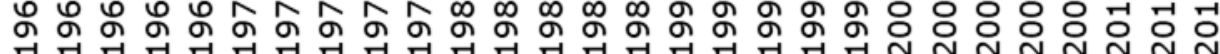

$\longrightarrow$ Precipitação média anual - - - Média histórica Linha de tendência linear

Figura 3 - Precipitação média anual da microrregião de Vitória de Santo Antão de 1960-2015.

A Figura 4 está representado o comportamento do IAC da microrregião de Vitória de Santo Antão. Constatou-se que as intensidades das chuvas possuem correlação com os eventos do EL Niño-Oscilação Sul (ENOS). 
Observou-se um total de 27 anos com anomalias negativas, variando entre anos secos (0 a -2), muito secos (-2 a -4) e extremamente secos (acima de -4); e 29 anos com anomalias positivas, classificadas em úmidos ( 0 a 2 ), muito úmidos ( 2 a 4) e extremamente úmido (acima de 4). Padrões de períodos chuvosos e secos podem ser observados ao longo da série. Até 1989 predominou anos mais úmido (10 anos de IAC negativos e 19 positivos e um de precipitação habitual ano 1967). A partir de 1990 ocorre o inverso com 17 anos de IAC negativos e 9 positivos, corroborando a linha de tendência de diminuição da precipitação.

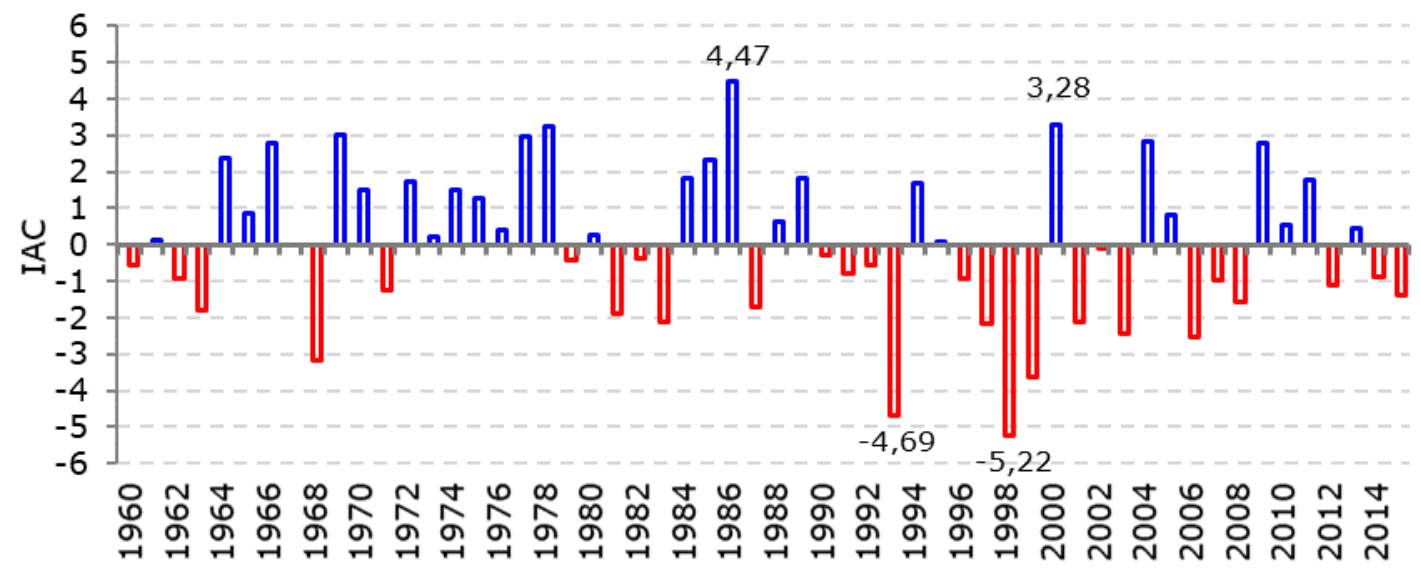

Figura 4 - Índice de anomalia de chuva da microrregião de Vitória de Santo Antão (19602015).

Os períodos chuvosos são: 1964-1978, apresentando um ano na média histórica e dois com IAC negativos, 1968 e 1971; 1984-1989, com o ano de 1987 de IAC negativo com -1,71; e 2009-2011, com IAC variando de úmido para muito úmido. O ano de 1986 foi o único extremamente úmido (4,47 IAC), apresentando uma precipitação de $1.595 \mathrm{~mm}$. Nos anos 90 foi ocorre grande intensidade de anomalias negativas principalmente em 1993 e 1998, os quais obtiveram precipitações de 510,2 e 445,2 mm e IAC de -4,69 e -5,2, respectivamente, classificando-os como extremamente secos. Esses anos coincidem com a ocorrência do El Niño de intensidade forte, acarretando secas severas no NEB, proporcionando em efeitos negativos nos ecossistemas aquáticos e perdas significativas na agricultura e pecuária, além de temperaturas altas e uma maior dificuldade na vida do campo (ALENCAR; BARBOSA; SOUSA, 2007).

A forte influência da variabilidade pluviométrica nas questões socioeconômicas da microrregião, bem como a tendência de diminuição da precipitação, revelou-se indispensável a análise das anomalias de temperatura da superfície do mar (ATSM) das regiões do NINO (1+2, 3, 4 e 3.4), da média do ENOS, dos oceanos Atlântico Norte e Sul, do Gradiente Norte-Sul de TSM do Atlântico, do Índice PA das regiões do NINO e do Índice PA da média das ATSM do oceano Pacífico + GRADT para a série de 1982-2015.

A Figura 5 revela as anomalias de temperatura da superfície do mar das regiões do NINO. Nela percebem-se pontos de inflexões positivos, os quais caracterizam aquecimento das águas superficiais do Pacífico, e negativos, resfriamento das mesmas. A influência dessas regiões do NINO sobre o IAC da microrregião estudada se dá basicamente pela proximidade ou afastamento do território americano. No primeiro caso, aquecimento, a ordem dos NINOS que mais 
influência nas anomalias negativas de chuva são: NINO 1+2, NINO 3, NINO 3.4 e NINO 4, podendo ser correlacionados aos períodos de IAC negativos: 1982-1983, 1990-1993, 1996-1999, 2001-2003, 2006-2008, 2012 e 2014-2015. Já no segundo caso que é o resfriamento das águas superficiais do Pacífico, as quais influenciaram nas anomalias positivas de chuva, isto é, chuvas acima da média, estão pela ordem de maior influência os NINO 3.4, NINO 4, NINO 3 e NINO 1+2, como se pode ver nos períodos de IAC positivos:1984-1986, 1988-1989, 1994-1995, 2000, 2004-2005, 2009-2011 e 2013.

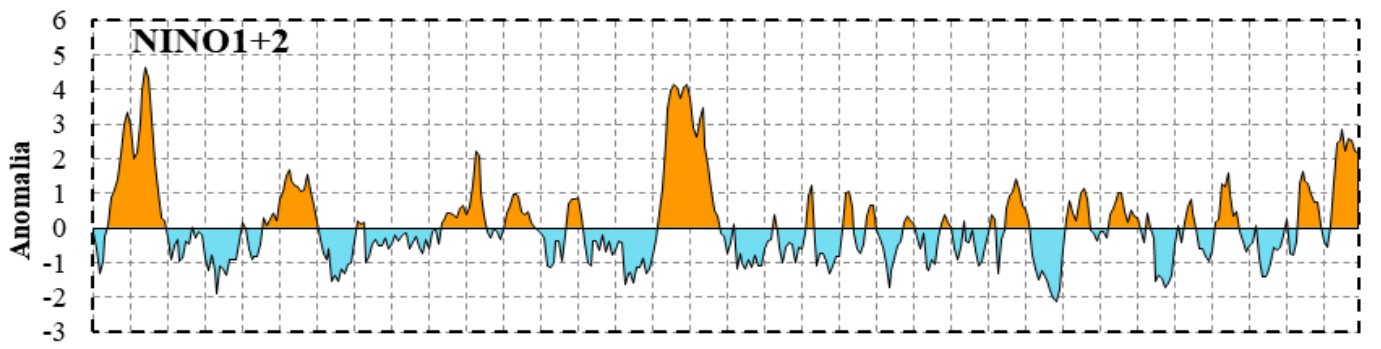

๙

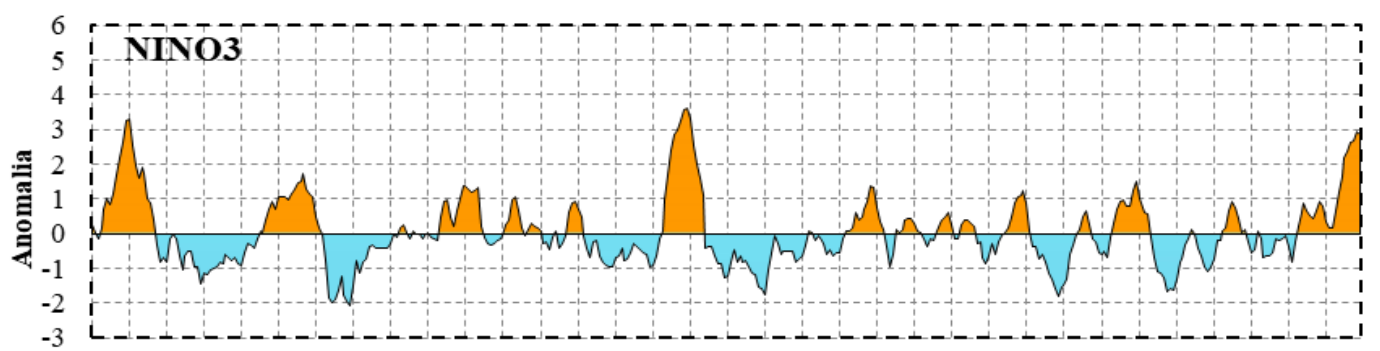

ڤొ

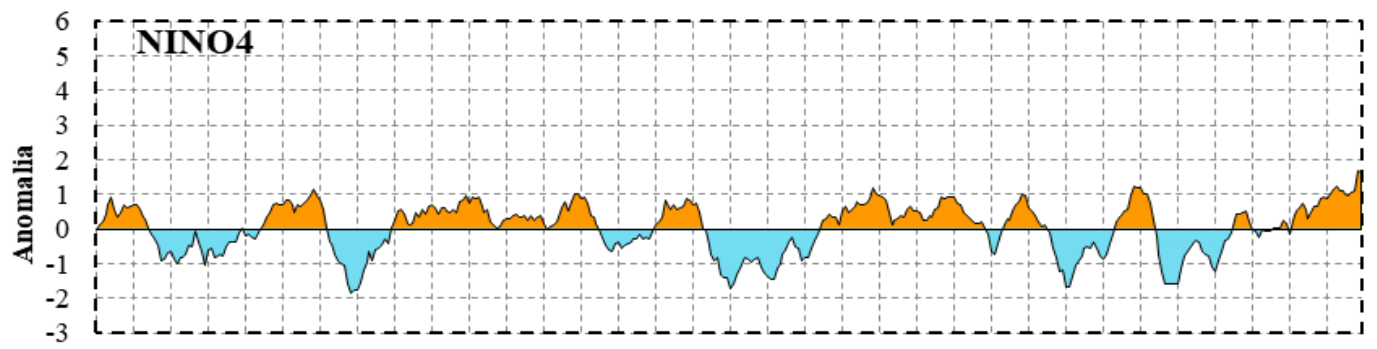

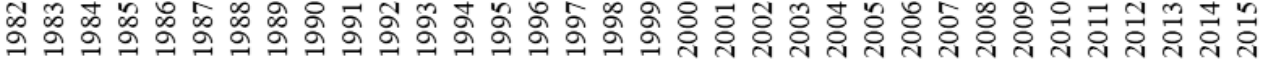

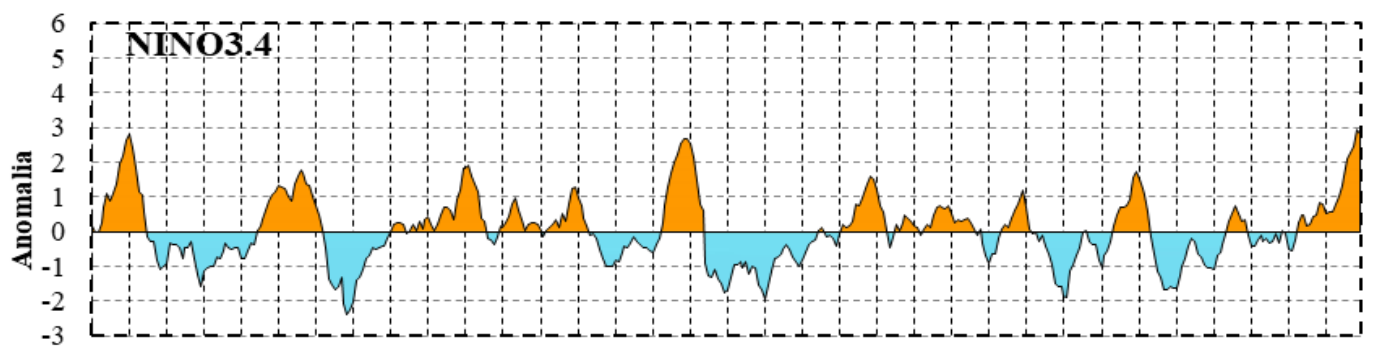

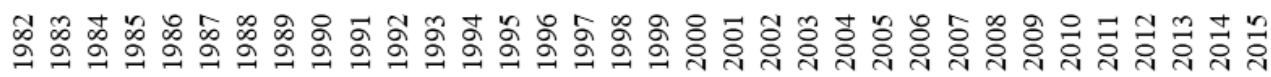

Figura 5 - Anomalias de temperaturas da superfície do mar das regiões do NINO (1982-2015). 
Os gráficos da Figura 6 evidenciam as tendências lineares das anomalias de Temperatura da Superfície do Mar das regiões do NINO. Neles se pode observar a variabilidade interanual das anomalias das TSMs ao longo da série. Nos pontos de inflexão constatou-se correlação com a quantidade de chuvas na área estudada. A exemplo disso pode-se destacar os anos de anomalias positivas 1983, 1987, 1997, 1998 e 2015, principalmente nas regiões do NINO1+2 e NINO3, como mencionado anteriormente, as regiões de teleconexões mais fortes com a quantidade de precipitação no lócus da pesquisa.

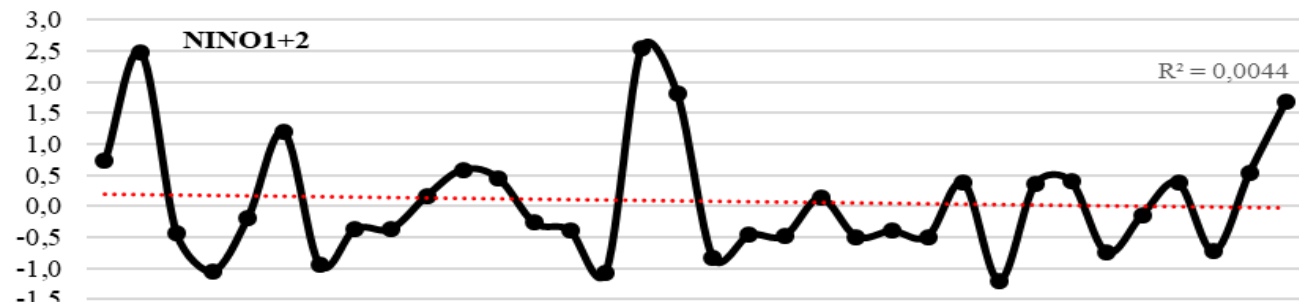

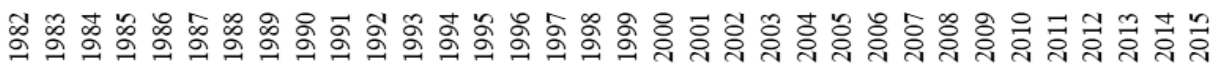

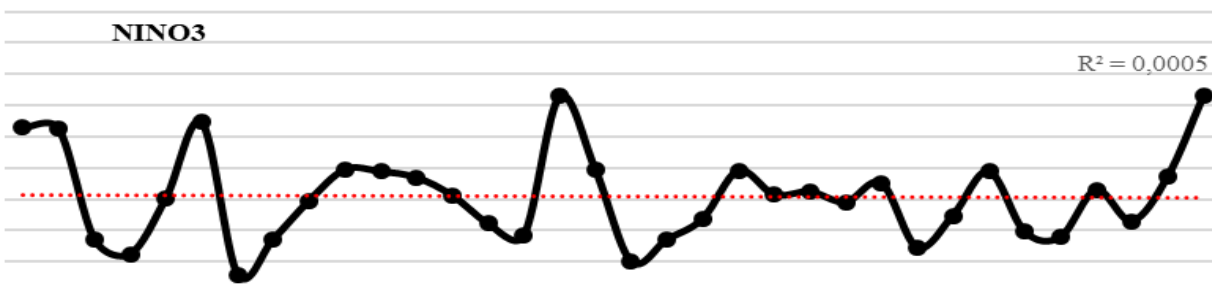

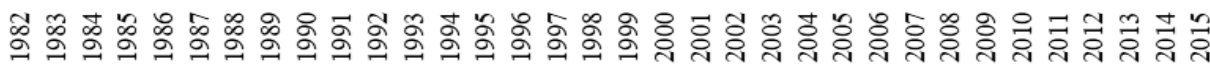

3,0

2,5

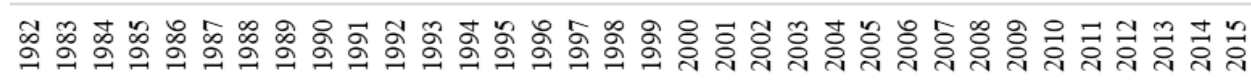

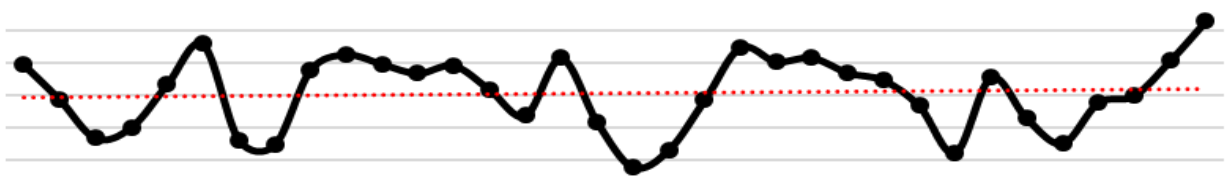

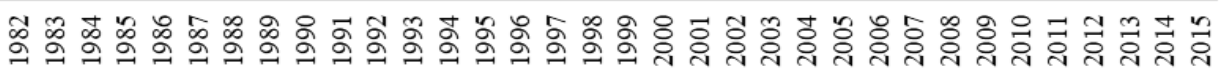

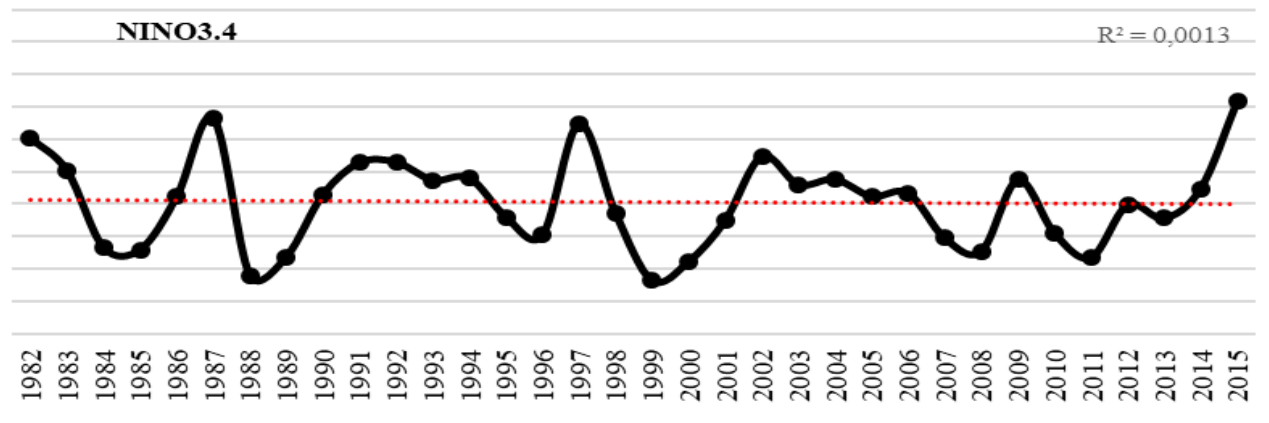

Figura 6 - Tendência linear das anomalias da TSM das regiões do NINO (1982-2015). 
Nesses supracitados anos (1983, 1987, 1997, 1998 e 2015), o IAC apresentou pontos de inflexão negativos, isto é, secas mais severas. Enquanto que nos anos de 1984, 1985, 1988, 1989, 2000, 2010, 2011 e 2013 obtiveram chuvas a cima da média (IAC positivos), revelando correlação com as anomalias negativas dos NINOS. É possível perceber um sutil decréscimo na tendência linear das TSMs nas regiões do NINO1+2, NINO3 e NINO3.4, já para a região do NINO4, menor poder de influência na precipitação da microrregião, é possível perceber um pequeno aumento na tendência.

A Figura 7 representa a média das anomalias de temperatura da superfície do mar das regiões do NINO $(1+2,3,4$ e 3.4). Como se pode perceber há uma similaridade entre as regiões do NINO e a média do ENOS, em que esta distingue com mais nitidez os períodos de anomalias positivas e negativas das TSMs, as quais revelam, como mencionado anteriormente, as teleconecções com os IACs negativos e positivos, respectivamente. Portanto, pode-se afirmar que mesmo com graus de influência diferentes das regiões do NINO sobre as chuvas ou secas na microrregião de Vitória de Santo Antão, bem como no Nordeste, a média do ENOS se mostra adequada a níveis de comparação com o IAC.

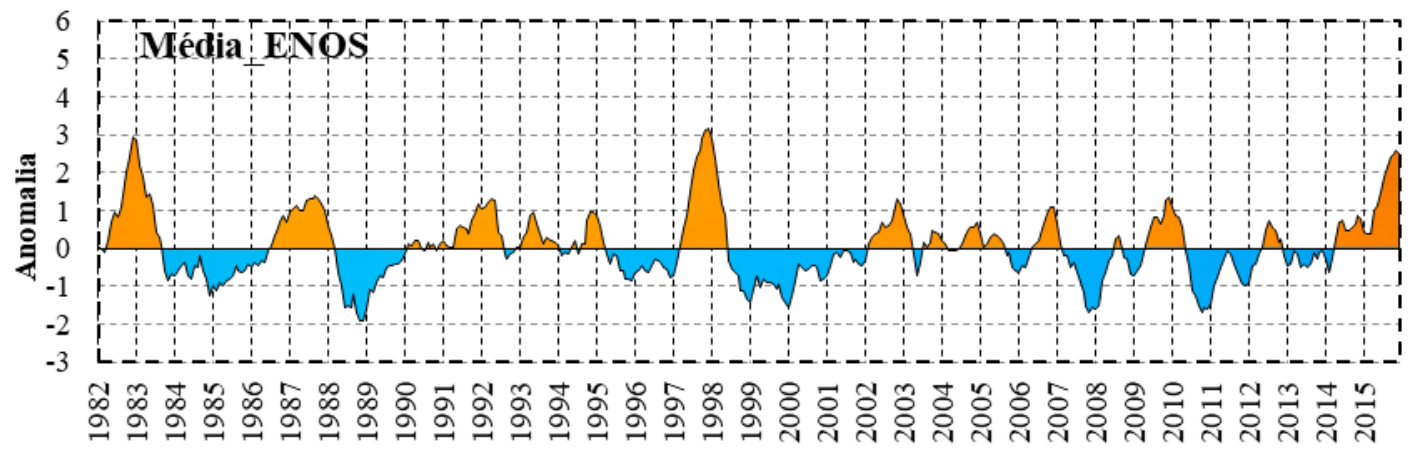

Figura 7 - Anomalia de temperatura da superfície do mar Média_ENOS (1982-2015).

A Figura 8 revela as médias das anomalias das TSMs das regiões do NINO, bem como sua estabilidade na tendência linear. A Média_ENOS corrobora a correlação entre as precipitações na microrregião e os padrões de anomalias da TSMs no Pacífico, em que os anos de anomalias mais altas nas regiões do NINO provocaram secas severas na microrregião, ao passo que anomalias mais baixas dos NINOs proporcionaram chuvas extremas, exceto para o ano de 1999, o qual revela as influências, não só das anomalias na temperatura da superfície do oceano Pacífico, mas também do Atlântico e do índice PA. 


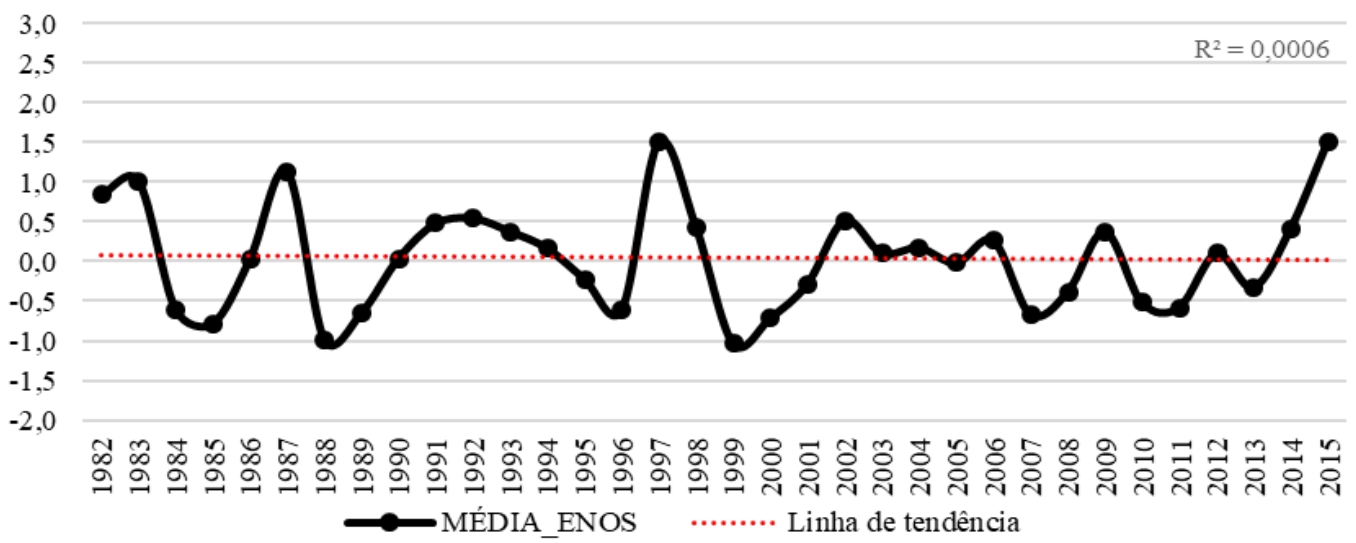

Figura 8 - Tendência linear das anomalias da TSM da Média_ENOS.

Outro fenômeno que influencia as chuvas no Nordeste é o Dipolo do Atlântico, diferença entre as ATSMs no oceano Atlântico Norte e no oceano Atlântico Sul. De tal modo, a Figura 9 apresenta a anomalia de temperatura da superfície do mar do oceano Atlântico Norte (NATL) e Sul (SATL) para a série analisada. No gráfico da NATL percebe-se dois grandes períodos distintos: o primeiro de 1982 a 1994 com predominância de anomalias a abaixo da média, exceto os meses de março a junho de 1983 e de março de 1987 até julho de 1988 expressivamente acima da média; o segundo de 1995 a 2015 com anomalias predominantemente a acima da média, com exceção de alguns meses dos anos de 1999 a 2003, 2014 e 2015 significativamente abaixo da média. O SATL mostrou-se mais irregular, predominando anomalias mensais superiores à média. Contudo, os períodos de anomalias abaixo da média se mostraram significativos, principalmente, até 1997.
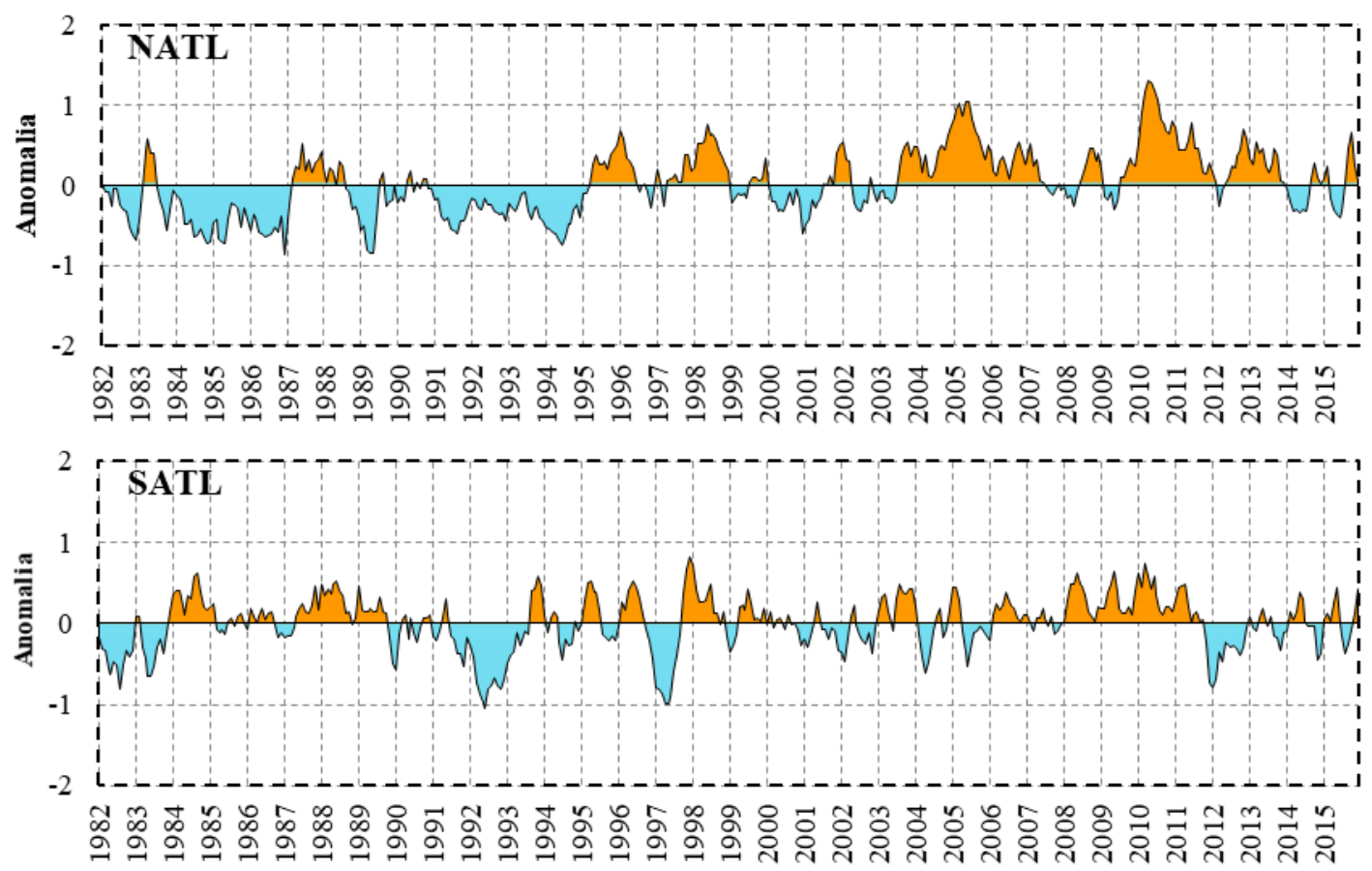

Figura 9 - Anomalia de temperatura da superfície do mar do oceano Atlântico Norte e Sul (1982-2015). 
Na Figura 10 é possível observar um expressivo aumento NATL e de maneira mais modesta no SATL. No NATL a variabilidade interanual é superior ao SATL, um dos fatores para essa diferença está na quantidade de terras emersas, as quais são superiores no hemisfério norte. Percebeu-se que os pontos de inflexão mais elevados $(1983,1987,1995,1998,2004,2005,2010)$ e os mais baixos (1984, 1986, 1989, 1994, 2000, 2009, 2014) no NATL contribuem para uma diminuição e um aumento das precipitações na microrregião, respectivamente.

O SATL também revelou forte influência no quantitativo pluviométrico da área pesquisada. Nos anos de pontos de inflexão negativos (1982, 1992, 1997 e 2012) ocorreram precipitações a baixo da média; e nas anomalias mais elevadas (1984, 1988 e 2010). No ano de 1992 deteve a maior anomalia negativa com $-0,75$ (temperatura média de $26,5^{\circ} \mathrm{C}$ ), intensificada nos últimos 3 meses do ano, o que influenciou em um IAC de -4,69 no ano de 1993.

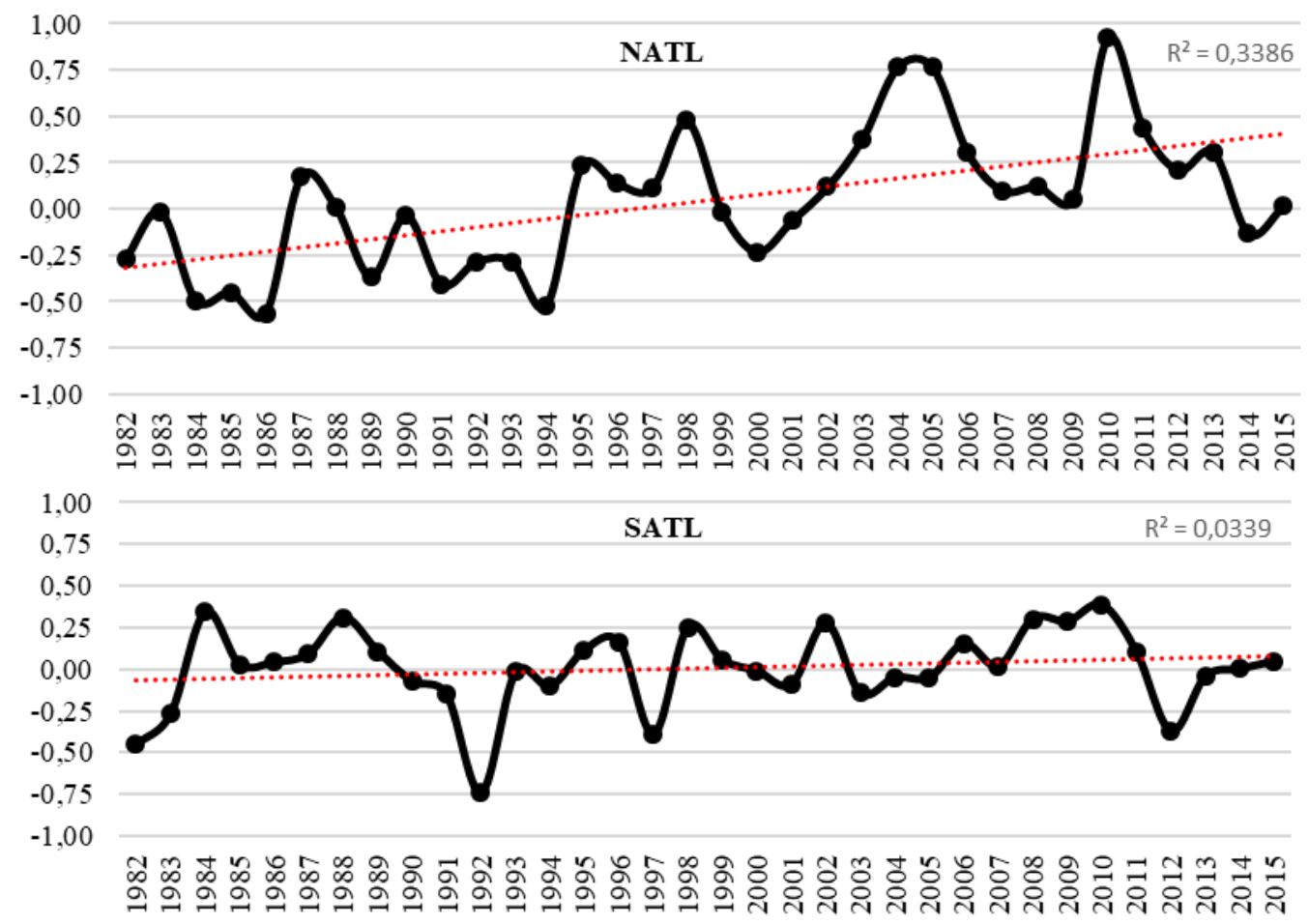

\section{Linha de tendência}

Figura 10 - Tendência linear das anomalias da TSM do Atlântico Norte (NATL) e Sul (SATL).

O gradiente Norte-Sul de TSM do Atlântico para o período analisado está representado na Figura 11, na qual predominou anomalias negativas até meados de 1995 e positivas a partir do mês julho de 1995. Verificam-se as teleconexões do GRADT com o IAC, pois quando o GRADT se apresenta positivo ocorre IAC negativo e quando o GRADT é negativo o IAC se mostrou positivo, na maioria das vezes. No entanto, deve-se considerar o ENOS e outros sistemas atmosféricos atuantes na área pesquisada, como Vórtices Ciclônicos de Altos Níveis (VCAN), Sistemas Ondulatórios de Leste (DOLs) e frentes polares por exemplo. 


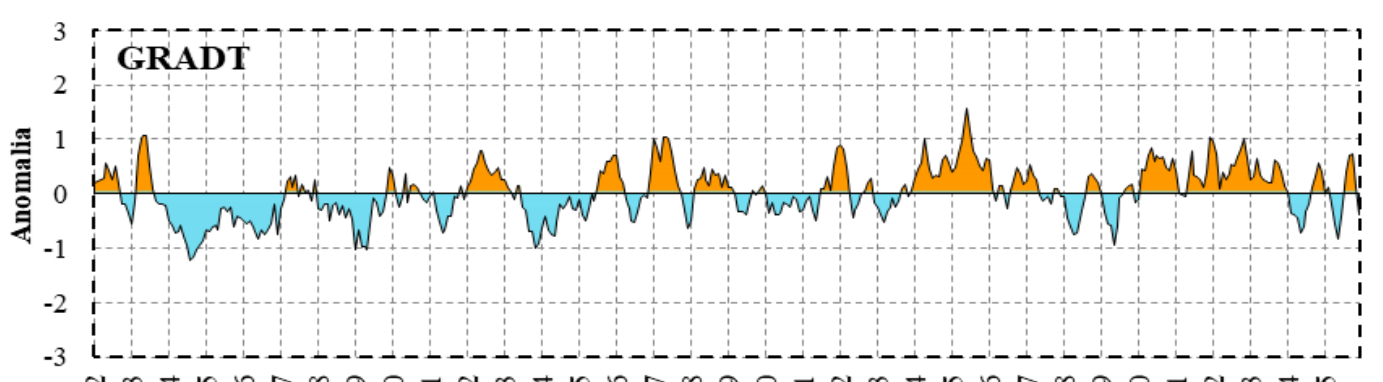

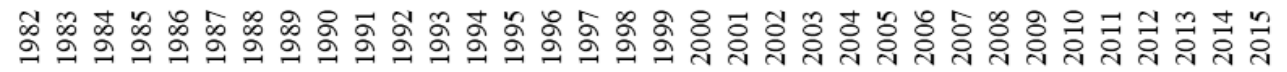

Figura 11 - Gradiente Norte-Sul de TSM do Atlântico (1982-2015).

$\mathrm{Na}$ Figura 12 o Índice PA (Pacífico Atlântico), como mencionado anteriormente, consiste na interação oceânica (ENOS+GRADT) por meio dos padrões de teleconexões em escala global. Nota-se que assim como as regiões do NINO que mais influência na precipitação na microrregião averiguada, o Índice PA também se mostrou mais atuante nas teleconexões de TSMs e pluviosidade na seguinte ordem crescente: PA_4, PA_3.4, PA_3 e PA_1.2. Nos PA_1.2 e PA_3 percebe-se variações expressivas e bem definidas no período de 1982 - 1999 , enquanto no período de 2000 - 2015 as variações são mais modestas e bastante irregulares. Já nos PA_3.4 e PA_4 há uma regularidade nos ciclos de anomalias positivas e negativas.

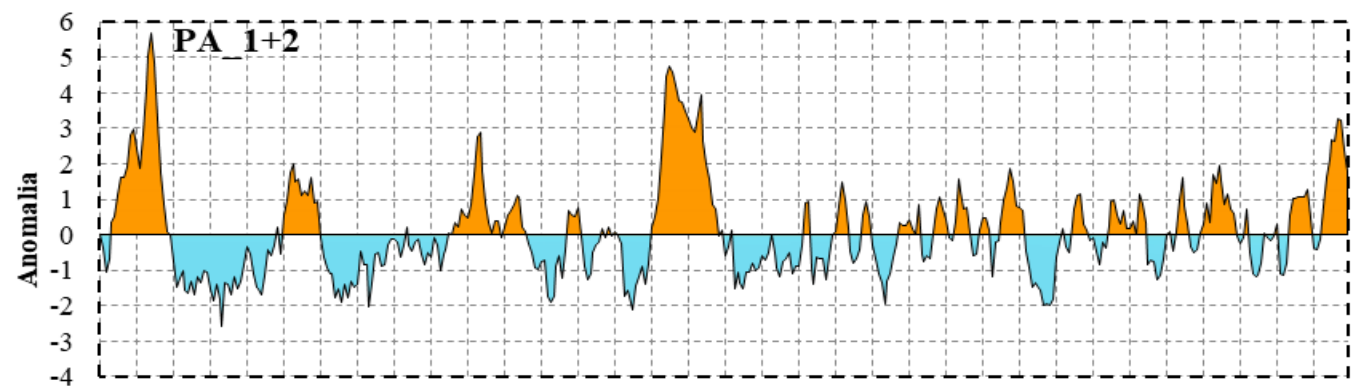

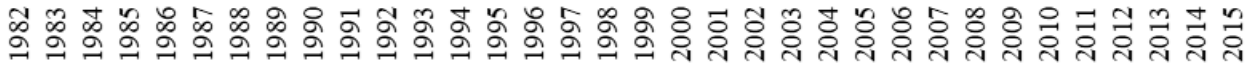

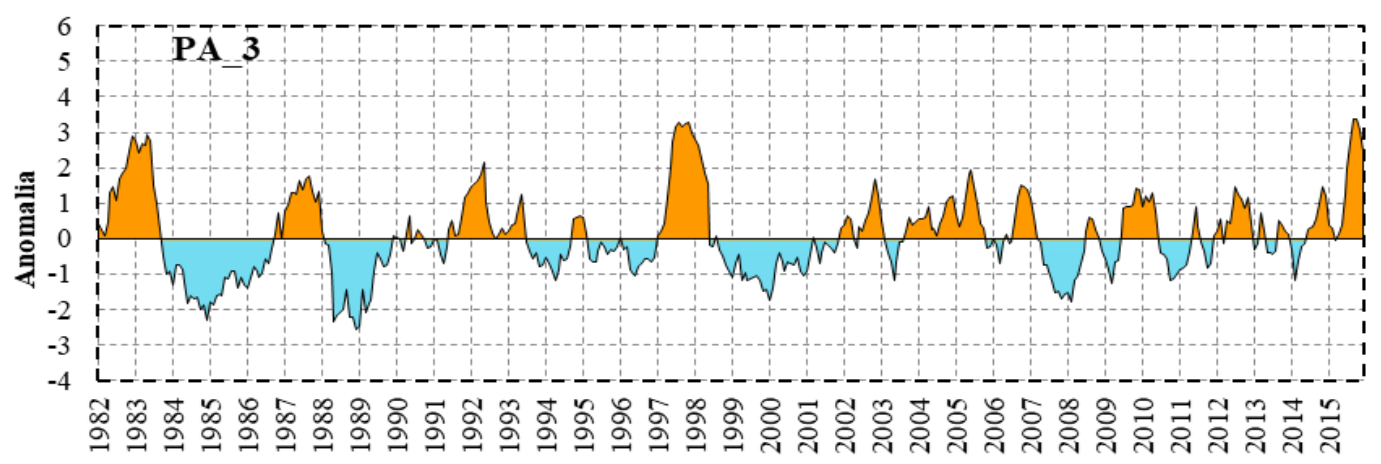




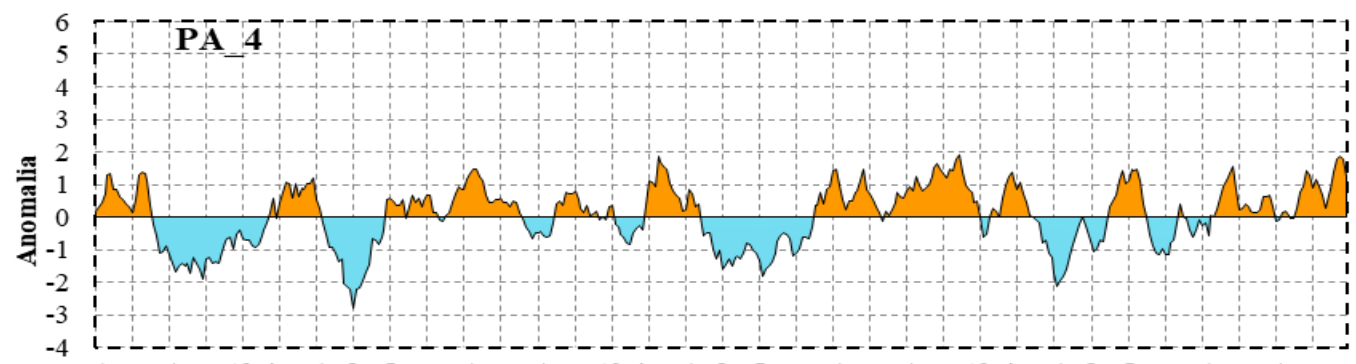

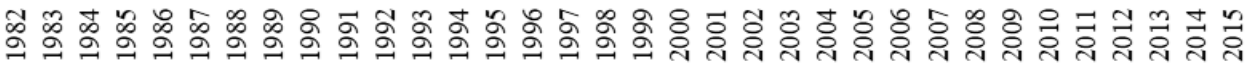

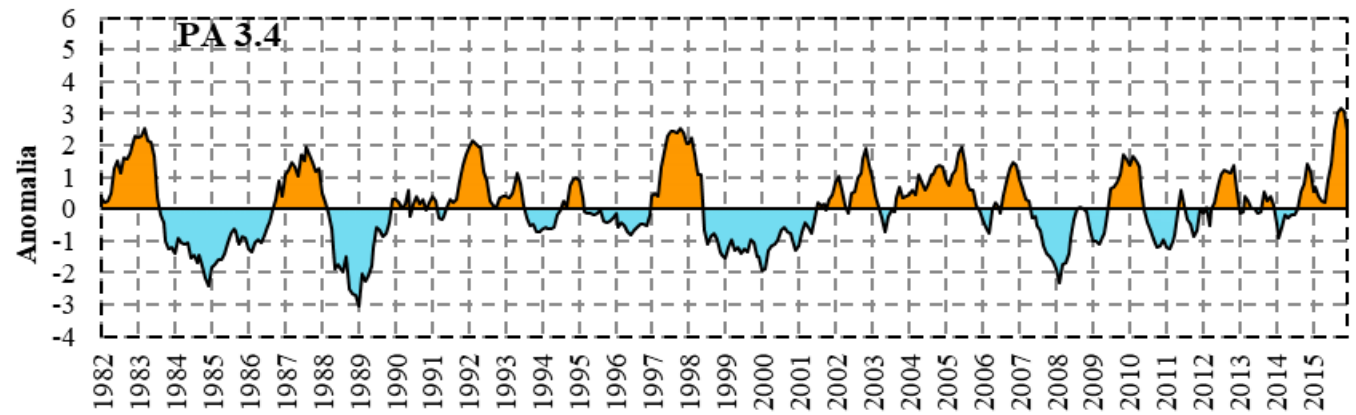

Figura 12 - Índice PA da região do NINO 1+2, NINO 3, NINO 4 e NINO 3.4 (19822015).

Com o Índice PA_Média (Figura 13) percebe-se maior regularidade nos ciclos de anomalias, sendo mais expressivos até o ano de 1999 e a partir de 2000 as anomalias são amenizadas, voltando a ser expressiva em 2015. Nos períodos de PA_Média positivos (1982 - 1983, 1987, 1990 - 1993, 1997 - 1998, 2001 - 2003, 2006, 2012 e 2014 - 2015) coincidiu com os períodos IACs negativos, bem como em suas respectivas intensidades, exceto para os anos de $2004-2005$ e $2009-2010$ que apresentaram alterações, contudo para estes se deve considerar também outros sistemas aqui mencionados, os quais influenciam e/ou determinam as chuvas na região como por exemplo: a ZCIT, DOLs e VACNs. Enquanto nos períodos de PA_Média negativos (1984 - 1986, 1988 - 1989, 1994 - 1995, 2000, 2011) correspondeu com os IACs positivos e sem suas concernentes magnitudes, observados nas Figuras 3 e 12, com exceção para 1996, 1999, 2007 - 2008 e 2013, nos quais ocorreram divergência, possivelmente pelos mesmos sistemas atmosféricos.

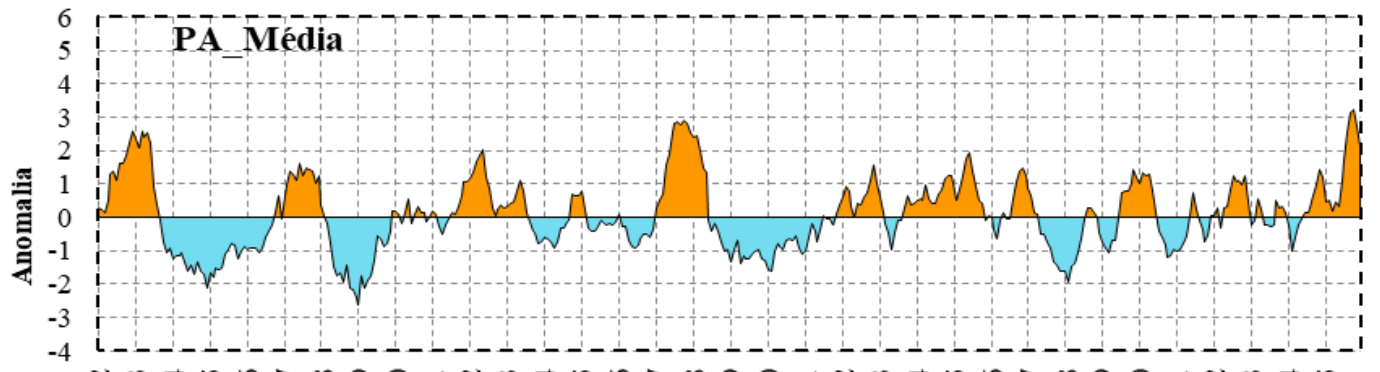

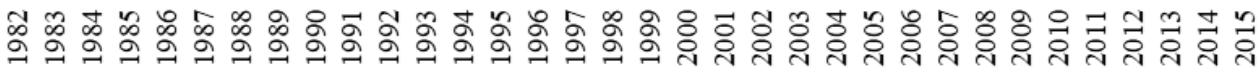

Figura 13 - Índice PA da média das ATSM do oceano Pacífico + GRADT (1982-2015). 
Por fim, buscou-se analisar as relações construtivas (anomalias de TSM entre esses oceanos que são favoráveis à ocorrência de chuvas acima da média) ou destrutivas (anomalias de TSM entre esses oceanos favorável à ocorrência de chuvas abaixo da média) por meio da análise de suas condições de ATSMs para os anos mais chuvosos e os mais secos. Na Tabela 2 o ano de 1985 apresentou uma relação construtiva com ATSMs negativas, índice PA de $-1,26$. No ano de 1986 (PA de -0,51) a ATSM Pacífico foi nula, mas o índice GRADT negativo, indicando ASTM superior no Atlântico tropical sul foi decisivo para a precipitação mais elevada $(1.595,1 \mathrm{~mm} / \mathrm{ano})$ da série analisada.

Em 2000 (PA de -0,93) ocorre o inverso, sendo o GRADT nulo e ATSM Pacífico negativa, contribuindo para a o segundo maior total anual de chuvas para a região. Para 2004 o índice PA foi de 0,69, sendo nula para ATSM Pacífico, contudo o GRADT positivo, indicando ATSM superior no Atlântico tropical norte, ocasiona uma condição favorável à ocorrência de chuvas abaixo da média (relação destrutiva). No entanto, a precipitação anual foi $1.403 \mathrm{~mm}$ considerado como um ano muito chuvoso. O ano de 2009 é considerado nulo para o GRADT e ATSM Pacífico, permanecendo com o índice PA em 0,14.

Tabela 2 - ATSM para os anos mais chuvosos na microrregião de Vitória de Santo Antão

\begin{tabular}{cccccc}
\hline Ano & Precipitação (mm) & IAC & GRADT & ATSM Pacífico & PA \\
\hline 1985 & $1.345,2$ & 2,32 & $-0,48$ & $-0,78$ & $-1,26$ \\
\hline 1986 & $1.595,1$ & 4,48 & $-0,60$ & 0,03 & $-0,51$ \\
\hline 2000 & $1.457,1$ & 3,29 & $-0,22$ & $-0,71$ & $-0,93$ \\
\hline 2004 & $1.403,0$ & 2,82 & 0,52 & 0,17 & 0,69 \\
\hline 2009 & $1.396,7$ & 2,76 & $-0,24$ & 0,38 & 0,14 \\
\hline
\end{tabular}

Na Tabela 3 representa a correlação entre as ATSM para os anos mais secos na área pesquisada. Nos anos de 1993, 1998, 2001, 2003 e 2006 são considerados neutros. Em 1983 o GRADT é considerado nulo, mas a ATSM Pacífico é positiva sobre o Pacífico tropical o que favorece à ocorrência de chuvas abaixo da média, a qual foi de 823,5 mm/ano, gerando um IAC de -2,1 (muito seco), sendo o índice PA de 1,26. No ano de 1997 com o GRADT e a ATSM positivos criando condições teoréticas ideais para uma relação destrutiva (chuvas abaixo da média). Com o índice PA de 2 a precipitação para esse ano foi de apenas $814,4 \mathrm{~mm}$ anuais.

Em 1998, ano mais seco com uma precipitação total de 445,2 mm, o IAC apresentou-se extremamente seco $(-5,23)$ com um GRADT de 0,22 e ATSM Pacífico de 0,43 , ambos considerados anos neutros. Essas condições de GRADT e ATSM Pacífico positivos apresentam uma relação destrutiva, a qual é favorável à ocorrência de chuvas abaixo da média. Com um índice PA atípico $(-1,12)$ para anos secos, o ano de 1999 apresentou um GRADT nulo e uma ATSM Pacífico negativa $(-1,03)$ o que favorece a ocorrência de chuvas acima da média, todavia a precipitação foi de $637 \mathrm{~mm}$ anuais, considerado como muito seco (IAC de $3,64)$. 
Tabela 3 - ATSM para os anos mais secos na microrregião de Vitória de Santo Antão

\begin{tabular}{cccccc}
\hline Ano & Precipitação $\mathbf{( m m})$ & IAC & GRADT & ATSM Pacífico & PA \\
\hline 1983 & 823,5 & $-2,10$ & 0,25 & 1,01 & 1,26 \\
\hline 1993 & 510,2 & $-4,69$ & $-0,27$ & 0,38 & 0,11 \\
\hline 1997 & 814,4 & $-2,17$ & 0,50 & 1,50 & 2 \\
\hline 1998 & 445,2 & $-5,23$ & 0,22 & 0,43 & 0,65 \\
\hline 1999 & 637,0 & $-3,64$ & $-0,09$ & $-1,03$ & $-1,12$ \\
\hline 2001 & 823,2 & $-2,10$ & 0,03 & $-0,28$ & $-0,25$ \\
\hline 2003 & 781,5 & $-2,45$ & $-0,16$ & 0,10 & $-0,06$ \\
\hline 2006 & 770,5 & $-2,54$ & 0,15 & 0,26 & 0,41 \\
\hline
\end{tabular}

Alves et al. (2015); Ribeiro (2016); Ribeiro e Maciel (2018) revelaram correlações entre eventos de El Niño com períodos secos no Nordeste Brasileiro e o La Niña para períodos de chuva. Nóbrega e Santiago (2014) afirmam que El Niño sozinho não é capaz de trazer períodos de seca severas na região, porém quando associado ao Dipolo do Atlântico podem intensificar tais períodos no NEB.

Nóbrega e Santiago (2016) observaram que quando foram analisados isoladamente a ocorrência de anomalias positivas sobre o Pacífico Leste e anomalias negativas sobre o Atlântico Sul, dipolo positivo, as secas são severas. Afirmam também que quando agem em conjunto essa influência é mais acentuada, ambas analises foram baseados nos dados do IAC. Rodrigues et al. (2017) analisaram a influência do ENOS sobre o regime de chuvas, em que os eventos de El Niño com intensidades variadas não explicam sozinhos os anos secos, assim como os eventos de La Niña não estão associados, necessariamente, a anos chuvosos, mas sim a interação desses fenômenos com os sistemas meteorológicos e o Dipolo do Atlântico é que são determinantes no regime de chuvas.

Salgueiro et al. (2016) analisaram a relação existente entre os eventos extremos no Nordeste do Brasil com as anomalias das TSM e os sistemas atmosféricos atuantes na região, no qual os resultados apontaram que os eventos extremos de secas e chuvas estão relacionados principalmente com a influência do Dipolo do Atlântico do que com o ENOS. As teleconexões das ATSMs do Pacífico e Atlântico com as anomalias de chuvas na microrregião de Vitória de Santo Antão são evidentes, contudo se salienta que os sistemas atmosféricos atuantes na área exercem forte influência no quantitativo de chuva, sendo necessário ampliar o estudo para os sistemas como Zona de Convergência Intertropical (ZCIT), Distúrbios Ondulatórios de Leste (DOLs), Vórtices Ciclônicos de Altos Níveis (VCANs) e Frente Atlântica.

\section{CONCLUSÕES}

De acordo com os resultados obtidos, verificou-se que o IAC é adequado para monitorar os períodos secos e chuvosos de uma região, bem como avaliar a variabilidade de precipitação pluviométrica, além de fornecer informações sobre a ocorrência, intensidade e impacto dos períodos chuvosos e secos o que auxilia no planejamento estratégico de uma localidade. Pode-se observar nesta 
pesquisa uma diminuição da pluviosidade na microrregião de Vitória de Santo Antão.

Foi possível observar uma relação expressiva entre as ATSMs dos oceanos Pacífico e Atlântico, bem como do índice PA com o IAC, tendo em vista que foram constatadas coincidências significativas entre os períodos e pontos de inflexões extremos de precipitação e as ATSMs das regiões do NINO. Constatouse também graus de influência diferentes das regiões do NINO sobre as chuvas ou secas na microrregião, a média do ENOS também se mostrou adequada a níveis de comparação com o IAC.

O estudo revelou um sutil decréscimo na tendência linear das TSMs nas regiões do NINO1+2, NINO3 e NINO3.4, já para a região do NINO4 é possível perceber um pequeno aumento na tendência, todavia a Média_ENOS mantevese estável. As anomalias da TSM no oceano Pacífico atuam de maneira favorável ou desfavorável na quantidade e intensidade de períodos chuvosos.

O GRADT apresentou expressivo aumento na TSM no NATL e de maneira mais modesta no SATL. Verificou-se também teleconexões do GRADT com o IAC, pois quando o GRADT se apresenta positivo ocorre IAC negativo e quando o GRADT é negativo o IAC se mostrou positivo.

Assim, na quantidade e intensidade dos índices pluviométricos da microrregião de Vitória de Santo Antão, bem como do NEB, deve-se considerar, além das ATSMs dos oceanos Pacífico e Atlântico (índice PA), outros sistemas atmosféricos atuantes na área, por exemplo: Vórtices Ciclônicos de Altos Níveis (VCAN), Sistemas Ondulatórios de Leste (DOLs) e Frentes Atlântica, essenciais para um planejamento estratégico.

\section{AGRADECIMENTOS}

O presente trabalho foi realizado com o apoio do Instituto Federal de Educação, Ciência e Tecnologia de Pernambuco (IFPE) e do Conselho Nacional de Desenvolvimento Científico e Tecnológico (CNPq), para os quais apresentamos nossos agradecimentos pela colaboração.

\section{REFERÊNCIAS}

ALENCAR, M. L. S. de; BARBOSA, M. P.; SOUSA, R. F. de. Efeitos do El Niño de 1997/1998 na produção agropecuária na bacia do Rio Sucuru - Cariri Paraibano, Revista Caminhos de Geografia, Uberlândia, v. 8, n. 24, 2007.

ALVES, A. M. B. et al. Eventos Extremos Diários de Chuva no Nordeste do Brasil e Características Atmosféricas. Revista Brasileira de Meteorologia, v. 32, n. 2, 227-233, 2017.

ALVES, M. F. A. et al. Análise do regime hídrico de Patos-PB por meio do Índice de Anomalia de Chuvas (IAC). Revista Verde, Pombal - PB, v. 10, n. 4, p. 42 - 46, 2015.

ARAÚJO, L. E.; MORAES NETO, J. M.; SOUSA, F. A. S. Análise Climática da Bacia do Rio Paraíba - Índice de Anomalia de Chuva (IAC). Engenharia Ambiental, v.6, n.3, p.508-523, 2009. 
BARREIRO, M.; CHANG, P.; SARAVANAN, R. Variability of the South Atlantic Convergence Zone simulated by an atmospheric general circulation model. Journal of Climate, v. 15, p. 745-763, 2002.

FREITAS, M. A. S. A Previsão de secas e a gestão hidroenergética: o caso da Bacia hidrográfica do Rio Parnaíba no nordeste do Brasil. In: Seminário Internacional Sobre Represas y Operación de Embalses. Puerto Iguazú, Anais... v. 1, p. 1-1, Puerto Iguazú: CACIER, 2004.

. Um sistema de suporte à decisão para o monitoramento de secas meteorológicas em regiões semi-áridas. Revista Tecnologia. Fortaleza, v. suplem., p. 84-95, 2005.

HASTENRATH, S.; HELLER, L. Dynamics of climatic hazards in Northeast Brazil. Quartely Journal Royal Meteorological Society, p, 77-92, 1977.

LUCENA, J. A. Anomalias de temperatura da superfície do mar, ritmo climático do semiárido brasileiro e repercussões socioeconômicas no núcleo de desertificação de Cabrobó/PE. Tese (doutorado), Universidade Federal de Pernambuco, CFCH, Recife, 2017.

MARCUZZO, F. F. N.; GOULARTE, E. R. P. Índice de Anomalia de Chuvas do Estado do Tocantins. Revista Eletrônica do Curso de Geografia. Jataí-GO, n. 19, p. 55-71, 2012.

MOLION, L. C. B.; BERNARDO, S. O. Dinâmica das chuvas no Nordeste Brasileiro. Congresso Brasileiro de Meteorologia, v. 11, Rio de Janeiro, p. 1334$1342,2000$.

NÓBREGA, R. S.; SANTIAGO, G. A. C. Tendências do controle climático oceânico sob a variabilidade temporal da precipitação no Nordeste do Brasil. Revista de Geografía Norte Grande, 63: 9-26, 2016.

NÓBREGA, R.S.; SANTIAGO, G.A.C.F. Tendência de temperatura na superfície do mar nos Oceanos Atlântico e Pacífico e variabilidade de precipitação em Pernambuco. Mercator, Fortaleza, v. 13, n. 1, p. 107-118, 2014.

OLIVEIRA, N. L.; MARCUZZO, F. F. N.; BARROS, R. G. Influência do El Niño e La Niña no número de dias de precipitação pluviométrica no Estado do Mato Grosso. Ciência e Natura. Santa Maria, v. 37 n. 4, p. 284-29, 2015.

RIBEIRO, A. M.; LUNARDI, D. M. C. A precipitação mensal provável para Londrina - PR, através da função gama. Revista Energia na Agricultura. Botucatu, v.12, n.4, p.37 -44, 1997.

RIBEIRO, E. P. Mudanças ambientais e desertificação na bacia hidrográfica do rio Pajeú. Tese (Doutorado em Geografia) - Universidade Federal de Pernambuco. Recife, 2016.

RIBEIRO, E. P.; MACIEL, A. S. Q. A.; Análise do Índice de Anomalia de Chuva na microrregião de Vitória de Santo Antão - Pernambuco. Revista GeoNordeste, n. 2, p. 89-106, 2018.

RODRIGUES, L. O. et al. Influência dos eventos de El Niño e La Niña no regime de precipitação do Agreste de Pernambuco. Revista Brasileira de Geografia Física, v.10, n.6, 2017. 
ROOY, M. P. V. A Rainfall Anomaly Index Independent of Time and Space. Notes, V.14, 1965.

SALGUEIRO, J. H. P. B. et al. Influence of oceanicatmospheric interactions on extreme events of daily rainfall in the Sub-basin 39 located in Northeastern Brazil. Revista Brasileira de Recursos Hídricos, 21, 685-693, 2016.

SANT'ANNA NETO, J. L. Clima e a organização do espaço. Boletim de Geografia, Maringá, v. 16, n. 1, p. 119-131, 1998.

SANTOS, A. P. P. et al. Precipitação na Cidade de Salvador: Variabilidade Temporal e Classificação em Quantis. Revista Brasileira de Meteorologia, v. 31, n. 4, 454-467, 2016.

SILVA, M. T.; et al. Influência da Temperatura da Superfície do Mar na Ocorrência de Linhas de Instabilidade na Costa Norte e Nordeste do Brasil. Revista Brasileira de Meteorologia, v. 32, n. 2, p. 261-268, 2017.

UVO, C. T. R. B.; et al. The influence of tropical Pacific and Atlantic SST on Northeast Brazil monthly precipitation. Journal of Climate, 1994 